\title{
Plant Science research productivity in Chile during the past 20 years
}

\author{
ERWIN KRAUSKOPF ${ }^{1,2,3}$
}

\author{
${ }^{1}$ Departamento de Ciencias Biológicas, Facultad Ciencias de la Salud, Universidad Andrés Bello, Santiago, \\ Chile \\ ${ }^{2}$ Fundación Ciencia para la Vida, Zañartu 1482, Santiago, Chile \\ ${ }^{3}$ MIFAB, Zañartu 1482, Santiago, Chile
}

\begin{abstract}
The purpose of this study was to carry out a bibliometric analysis of the articles published in Chile during 1987-2006 that were categorized into the Plant Science discipline by ISI. The data was extracted from the Web of Science database, obtaining a total of 911 articles for analysis. Almost half of the articles were the outcome of an international collaboration, the United States being the country with more collaborative links with Chile within this discipline. A list was made with the 10 most-cited articles and 10 most frequently used journals. The analysis showed that almost $50 \%$ of the articles were concentrated in 10 different journals. The number of articles produced each year revealed a steady growth in scientific production since 1987. This is probably related to the progressive interaction between industry and public-research institutions.
\end{abstract}

Key terms:

\section{INTRODUCTION}

It was in the early 1980 s that Chile introduced modifications in its economic policies that promoted a change towards an export-oriented economy (Gwynne, 1999). The country became aware of the advantage of having vast renewable (i.e. fruits, wood, animals) and non-renewable (i.e. copper) natural resources. Many countries, such as Australia, Sweden and Finland, have based their development strategies on natural resources (Maloney, 2002). Much of the knowledge generated on natural resources has been obtained by research done at universities and institutions around the world.

In the last three decades plant science has become a broad discipline, shifting from the traditional focus on plant taxonomy, physiology and morphology into areas such as developmental biology, molecular and cellular biology, genomics and proteomics. This shift is due to the impact plant science has had in economically important areas, such as agriculture, horticulture, forestry, and energy.

Bibliometric studies analyzing research output of Chilean institutions in several biological disciplines have established their trends over several years (Krauskopf, 2002). However, an analysis of the Plant Science discipline has never been made. Thus, the objective of this study is to assess the evolution of Plant Science research in Chile from 1987 to 2006.

\section{METHODS}

Using the ISI Web of Science database, a query was made (on July $27^{\text {th }}, 2007$ ) that searched for records that were published from 1987 to 2006 and that were registered to Chile. All records that were categorized 
as "Plant Science" among the ISI disciplines were retrieved. The documents were analyzed according to their type, language of publication, most frequently used journals and most frequently cited articles. For this study, records that were categorized as "meeting abstracts" and corrections were discarded.

The SCIMAGO country and rank database (SCIMAGO, 2007) was used to search for publications within the "Plant Science" discipline that were published by different countries from 1996 to 2006.

As well, the ISI Journal Citation Report (JCR) database for the year 2006 was used to obtain the impact factors of the most frequently used journals.

\section{RESULTS}

Over the 20-year period analyzed, a total of 911 papers were published that were categorized by ISI as belonging to the "Plant Science" discipline. As observed in Figure 1, an upward trend is observed in the number of papers published each year. To quantify this increase, an average of the number of papers was taken every five years, estimating an average of 39.4 papers/ year for the period 1987-1991, followed by the $1992-1996$ period with 40.6 papers/ year, 1997-2001 with 47.2 papers/year and 2002-2006 with 55 papers/year. As a country, Chile ranked number 43 (among
197 countries) in the number of papers produced, surpassed in South America by Argentina (ranked 19) and Brazil (ranked 13), according to the SCImago database (SCImago, 2007). Nevertheless, an analysis on the average number of cites per paper established that Chile (6.01 cites/paper) was superior in this indicator compared to Brazil (5.2 cites/paper) and Argentina (5.65 cites/paper).

The top ranking institutions in Chile that published within this discipline during the 20-year period were Universidad de Chile with 334 publications (36.7\%), followed by Pontificia Universidad Catolica de Chile with 156 publications $(17,1 \%)$, Universidad Austral de Chile (81 publications; 8.9\%), Universidad de Santiago de Chile (57 publications; $6.3 \%$ ) and Universidad de Talca (55 publications; 6.0\%). Among the 911 articles published in Chile, 448 (49\%) originated solely from Chilean institutions, while the remainder resulted from international collaborations with 51 different countries, the most productive collaboration being with the United States (116 articles; $12.7 \%$ ), followed by Spain (99 articles; $10.8 \%$ ) and Germany (75 articles; 8.2\%). The distribution of document type throughout the 20-year period was studied. The most frequently document type used was "article" that comprised $88.8 \%$ of the total production, followed by "note" $(7.4 \%)$, "review" (1.4\%), "letter" (1.3\%) and news item $(0.9 \%)$.

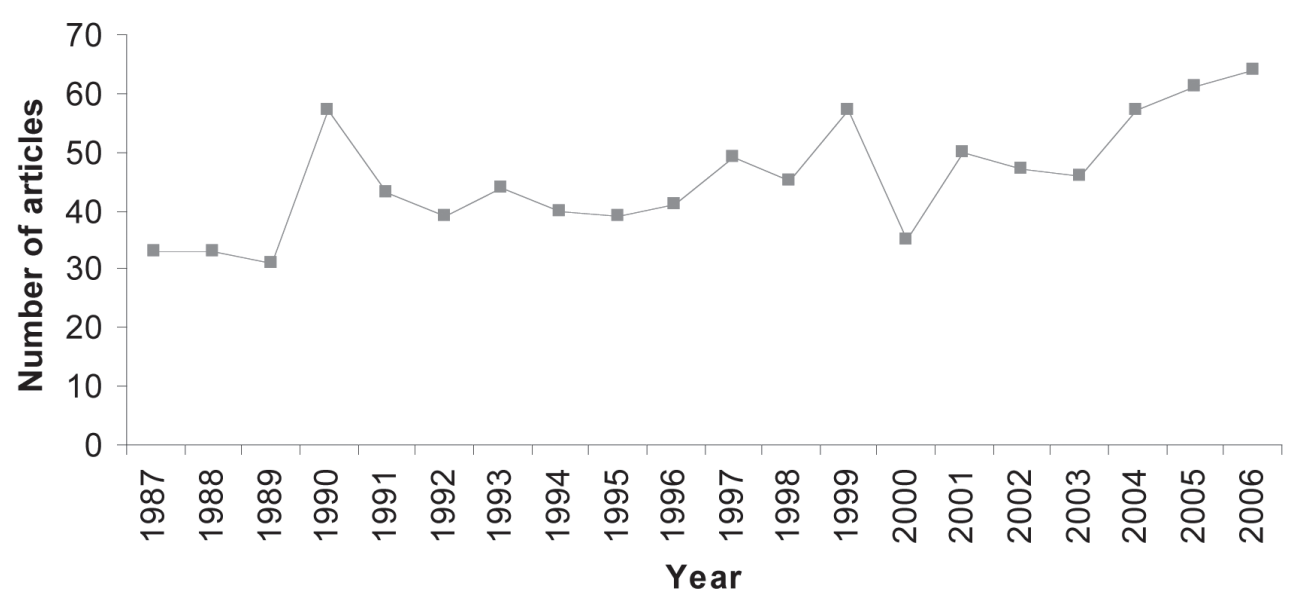

Figure 1: Number of articles published within the Plant Science discipline during 1987-2006. 
Most of the articles were written in the English language, accounting for $95.4 \%$ of the total number of articles. This was followed by articles in Spanish $(30 ; 3.3 \%)$, German $(6 ; 0.7 \%)$, French $(5 ; 0.5 \%)$ and Portuguese $(1 ; 0.1 \%)$. The fact that a high number of articles was written in English language is not surprising, as the majority of the ISI journals within this discipline use English as the official language. A glimpse at the six articles published in German showed that they were published in German journals, with an author in common. Likewise, the articles published in French were in Canadian and French journals.

The number of citations a particular article receives is a measure of its visibility to other researchers. Thus, the citations of articles categorized as Plant Science ranged from a minimum of 0 to a maximum of 306 citations (Table 1). In fact, the most-cited article in Plant Science was positioned among the top 40 most-cited articles published by a Chilean-registered institution within the 20 year period analyzed. Ranking a distant second, an article with 108 cites was observed. In contrast, 127 articles (14\% of the total number of articles) had not been cited, including 45 articles published prior to the year 2001 .

There are currently 147 journals categorized as belonging to the Plant Science discipline, with impact factors ranging from 0 to 19.837 (for the Annual Review of Plant Biology), with a median impact factor of 0.818 . The impact factor of a journal is defined as the number of current citations to articles published in the previous two years divided by the total number of articles published in the previous two years. Table 2 shows the ten most utilized journals by researchers from Chilean institutions, the number of articles, percentage of total articles and journal impact factor. As observed in Table 2, over $20 \%$ of the articles published in the 20 -year period have been published in Phytochemistry, an English journal ranked $24^{\text {th }}$ among all journals from this discipline,

TABLE 1

The 10 most-cited articles published in the field of Plant Science from 1987 to 2006

\begin{tabular}{|c|c|c|c|c|c|}
\hline Journal & Year & Vol & Pages & Title & es cited \\
\hline Phytochemistry & 1988 & 27 & $3349-3358$ & $\begin{array}{l}\text { Hydroxamic acids (4-hydroxy-1,4-benzoxazin } \\
-3 \text {-ones), defense chemicals in the gramineae }\end{array}$ & 306 \\
\hline Vegetatio & 1987 & 69 & $109-114$ & $\begin{array}{l}\text { A hierarchical consideration of causes and } \\
\text { mechanisms of succession }\end{array}$ & 108 \\
\hline Systematic Botany & 1995 & 20 & $55-64$ & $\begin{array}{l}\text { ITS sequences and the phylogeny of the genus } \\
\text { Robinsonia (asteraceae) }\end{array}$ & 81 \\
\hline Botanica Marina & 1987 & 30 & $151-165$ & $\begin{array}{l}\text { The arrival of seaweed propagules at the shore - } \\
\text { a review }\end{array}$ & 69 \\
\hline Phytochemistry & 1991 & 30 & $3177-3184$ & Cold-acclimation in plants & 61 \\
\hline Phytochemistry & 1989 & 28 & $447-449$ & $\begin{array}{l}\text { Changes in hydroxamic acid levels of wheat } \\
\text { plants induced by aphid feeding }\end{array}$ & 60 \\
\hline Phytochemistry & 1990 & 29 & $3773-3775$ & Antioxidant activities of lignans and flavonoids & 58 \\
\hline Sytematic Botany & 1987 & 12 & $435-443$ & $\begin{array}{l}\text { Allozyme divergence and the evolution of } \\
\text { Drendroseris (compositae, lactuceae) on the } \\
\text { Juan-Fernandez islands }\end{array}$ & 57 \\
\hline $\begin{array}{l}\text { Theoretical and } \\
\text { applied genetics }\end{array}$ & 1996 & 92 & $532-540$ & $\begin{array}{l}\text { Comparison of four molecular markers in } \\
\text { measuring relationships among the wild potato } \\
\text { relatives Solanum section Etuberosum } \\
\text { (subgenus Potatoe) }\end{array}$ & 55 \\
\hline Planta Medica & 1996 & 62 & $98-105$ & Plant metabolites active against Trypanosoma cruzi & 54 \\
\hline
\end{tabular}


TABLE 2

The 10 most used journals with the number of records and their impact factor for the year 2006

\begin{tabular}{lcc}
\hline Journal Title & Record count & Impact factor \\
\hline Phytochemistry & $201(22.1 \%)$ & 2.417 \\
Journal of natural products & $51(5.6 \%)$ & 2.418 \\
Journal of Ethnopharmacology & $43(4.7 \%)$ & 1.625 \\
Phyton-International Journal of Experimental Botany & $39(4.3 \%)$ & $*$ \\
Planta Medica & $31(3.4 \%)$ & 1.746 \\
Journal of Phycology & $29(3.2 \%)$ & 2.580 \\
Communications in Soil Science and Plant Analysis & $28(3.1 \%)$ & 0.302 \\
Plant Disease & $25(2.7 \%)$ & 1.795 \\
Plant Ecology & $24(2.6 \%)$ & 1.383 \\
Botanica Marina & $21(2.3 \%)$ & 1.009 \\
\hline
\end{tabular}

*: last impact factor registered at JCR was for the year 2001.

that publishes 24 issues per year. The other nine journals concentrated $31.9 \%$ of the articles published within the discipline. The Argentinean journal Phyton-International Journal of Experimental Botany was discontinued in the year 2002, therefore the impact factor for this journal was not included in the table.

The number of articles published within the Plant Science discipline revealed a sustained constant growth throughout the 20 -year period analyzed. Part of this could be attributed to a recently formed interaction between universities and private industry. The latter has seen these public institutions as a place to solve some of the problems facing the agriculture/forestry industry. Currently, the majority of the public universities have created a unit in charge of increasing their interaction with the productive sector (Bernasconi and Rojas, 2004). There are some government programs in Chile that promote this linkage, such as Fondo de Fomento al Desarrollo Científico y Tecnológico (FONDEF, managed by CONICYT) and GENOMA (managed by CORFO). These programs have introduced economic resources that assist public institutions to finance their research in order to solve problems facing the horticulture/forestry industry (Orellana, 2004). For instance, between 1996 and
2004 FONDEF provided funds for 130 projects in the Agricultural/Forestry sector (FONDEF, 2008). As a requirement, each of these projects needs to have a counterpart from private industry that finance at least $25 \%$ of the total cost of the project. A more recent example of this interaction was the formation of the Forestry Genomic Consortia, which integrated Universidad de Concepcion with Fundacion Chile, Forestal Arauco and Forestal Mininco, with the objective of developing biotechnological, molecular and bioinformatical tools to strengthen the genetic improvement programs being driven by the two largest forestry holdings in Chile. Another example is the Fruit Consortium, which not only brought together universities with over 20 differentsized fruit companies, but also included the fruit guild association as a member of this consortium.

From the articles published within this discipline, $51 \%$ resulted from international collaborations. This percentage is almost the same as the one established for the country during the 1999-2003 period (Glanzel et al., 2006). The most frequent collaboration was with research groups from the United States, a relation that also produced four of the 10 most-cited articles listed in Table 1. Even though Spain turned 
out to be the country with which Chile had the second most frequent international collaboration, no highly cited article resulted from this interaction. Instead, collaboration with German research groups produced one of the 10 most-cited articles. It is worth pointing out that the other five articles listed on Table 1 were produced solely by Chilean institutions. The fact that most of the articles were published in English and in journals that were over the median impact factor for the discipline, has certainly allowed for an increase in the visibility of the research being performed in Chile.

In brief, this study reveals a steady increase in scientific production within the discipline of Plant Science that is fulfilling the needs of not only the scientists driving the research, but also the needs of industry. It would be interesting to establish in 10 years time if the current scientific-policy, funded by the royalties obtained from the mining industry, will boost the current productivity within the plant science discipline.

\section{REFERENCES}

BERNASCONI A, ROJAS F (2004) La educación superior y el contexto social y económico. En: Informe sobre la Educación Superior en Chile 1980-2003, Editorial Universitaria. pp: 63-84

FONDEF (2008) Numero de proyectos por Area Prioritaria Investigación y Desarrollo. En: http://www.fondef.cl/

GLANZEL W, LETA J, THUS B (2006) Science in Brazil. part 1: A macro-level comparative study. Scientometrics 67: 67-86

GWYNNE RN (1999) Globalization, commodity chains and fruit exporting regions in Chile. Tijdschrift voor Economische en Sociale Geografie 90: 211-225

KRAUSKOPF M (2002) A scientometric view of some biological disciplines in Chile. Biol Res 35: 95-99

MALONEY WF (2002) Innovation and growth in resource rich countries. Latin American and Caribean Region The World Bank. pp 37

ORELLANA C (2004) Chile launches policy to boost biotech. Nature Biotechnology 22(1): 7-8

SCIMAGO (2007) SJR - SCImago Journal \& Country Rank. http:.//www.scimagojr.com 
